\title{
Taking Risks and Breaking New Frontiers: Introduction to the Special Issue and the Cardinal Challenges for Policy \& Politics Scholarships
}

by

Oscar Berglund, Claire A. Dunlop, and Christopher M. Weible

Cite as:

Berglund, O., Dunlop, C.A. and Weible, C.M. (2022) Taking Risks and Breaking New Frontiers: Introduction to the Special Issue and the Cardinal Challenges for Policy \& Politics Scholarships, Policy \& Politics 50, 1

\begin{abstract}
This Special Issue makes a statement about the study of policy and politics, where it has been, how it is done, what it is, and where it is going. When addressing the question 'who gets to speak for our discipline?' we respond emphatically - many people, from many places, working in many ways. It comprises scholarship that has rarely been combined to explore some cardinal challenges about our scholarships: (1) How do we conceive of policy and political studies? (2) To what extent should our science be "normative" or "objective" or "positive"? (3) Who are our audiences, and how do we engage them? (4) Whose knowledge matters, and how does it accumulate? (5) How should we advance the study of policy and politics? We conclude charging the field to consider different ways of thinking about what we can discover and construct in the world and how we can conduct our science.
\end{abstract}

Key Words: public policy, policy processes, policy theories, policy design, politics 


\section{Our Motivation - From Metacommunities to New Frontiers}

The study of policy and politics has reached a pivotal point in its development as a 'science'. Looked at from one perspective, there are signs of vitality across a range of areas. Most notably, we see this in the ongoing growth in approaches, theories, techniques, insights, and methods supported by diverse metacommunities (Berglund et al., 2021). We use the term metacommunities to refer to the different groups of scholars connected yet also separated in developing their science and understanding of certain aspects of policy and politics. Frequently supported by their journals and conferences, these metacommunities sometimes operate from different ontological, epistemological, and methodological orientations. In many ways, this exemplifies the view that the 'house of science has many rooms' (Yanow 2005). Given their different foci and ways of knowing, they have created impressive reservoirs of knowledge over the decades.

From another perspective however, these same metacommunities divide the field, and are often associated with the negatively connoted term "silos". As knowledge and distinct professional languages develop, so does the distance in developing common understandings, challenges in communicating, and lost opportunities for collective learning. Research becomes settled into paradigmatic programs where risk-taking the exception rather than the rule. The deleterious consequences of this are considerable. We have long known that while it generates profound insights on aspects of the policy process and design, the granularity of policy research means it can struggle to engage fully with the big questions facing our societies. Yet, how the research of our metacommunities can help address big social problems like inequality, the de-legitimization of expertise or democratic back-sliding is one of the most pressing challenges we face as policy scholars (Dunlop and Radaelli 2021).

We need metacommunities to support research programs and groups of scholars in developing and growing their science. Certainly, we should not do away with them. Indeed, the research activities that happen in metacommunities might be the primary source of success in the broader field of policy and politics - with firm foundations established we can afford to take risks and experiment on higher wires addressing big challenging socio-political problems. Yet, what happens when the source of our strengths also become the source of our weaknesses? How can we ensure the reservoirs filled by distinct groups becomes common pools from which we can all draw?

This Special Issue on Taking Risks and Breaking New Frontiers springs from the assumption that we can gain additional knowledge by supporting the integrity of the research conducted in metacommunities and building connections between them. This collection comprises scholarship that has rarely been combined in such a collage to highlight the diversity of the field and opportunities for learning. As editors, we challenged these authors to summarize what is known in their area of study, what challenges exist for inclusivity, diversity, and relevance, and the needs and strategies for advancement. As we discuss below, from each of their responses and the collection, five cardinal challenges emerged for the field to grapple with as it matures and grows towards realizing its ideals and aspirations. 


\section{Rendering Meaning and Significance of this Special Issue}

This Special Issue makes a statement about the study of policy and politics, including where it has been, how it is done, what it is, and where it might be going. The first interpretation of this arises from a surface scan of the titles and authors.

From this perusal, we see authors from divergent research programs (i.e., metacommunities). Indeed, this collection of articles breaks the mold of what we usually see in conventional special issues. Special issues typically include a compilation of authors and research that might represent one topic, one theory or one family of related theories, one view of science, one cant, and so forth. In other words, most special issues focus on one of the singularities found in policy and politics, meaning one community of scholarship and, thus, one voice.

Instead, this Special Issues breaks from this orthodoxy to form a new mold marked by a value for comprehensiveness and inclusiveness. When addressing the question 'who gets to speak for our discipline?' we respond emphatically - many people, from many places, working many ways. And so, this new mold brings together a diversity of scholars and scholarship. The Special Issue includes, for example, Tanya Heikkila and Michael D. Jones (2022), leading experts in mainstream policy process theories, and Anna P. Durnová (2022), a leading expert in interpretive approaches and emotions. It includes issues of identity pertinent to policy and politics with Emanuela Lombardo and Petra Meier's (2022) focus on gender and policy studies and a generic focus on policy designs by Saba Siddiki and Cali Curley (2022). Finally, it includes a broad view of global public policy studies by Osmany Porto de Oliveira (2022) and a view from the public with Jae Moon and Shine Cho’s (2022) focus on public policy and citizens.

While this Special Issue certainly falls short of representing the entirety of studies of policy and politics - as if any special issue could - its meaning and significance drawn from a casual perusal of its contents suggest something new.

\section{Posing Five Cardinal Challenges for Studying Policy and Politics}

The meaning and significance of this Special Issue prompt a fresh look into the foundations of policy and political studies. Indeed, we see this collection posing five cardinal challenges about our scholarships.

\section{How do we conceive of policy and political studies?}

As one of the foundations of the study of public policy, Harold D. Lasswell provided the vision: deploy the arsenal of the social sciences to study the most pressing problems facing humanity by understanding the context and providing problem-oriented advice in the service of democracy and toward the greater realization of human dignity (Lasswell, 1948, 1951). The charge was not just to conduct research. Rooted in American pragmatism, Lasswell's vision can also be encapsulated into a single phrase: knowledge to action (Dunn, 2019). Yet, despite Lasswell's vision as grandeur, at the time, most political scientists either rejected this message or failed to understand the symbols and significance embedded in it (deLeon, 1989). Today, we see ongoing interpretations and attempts at communicating Lasswell's scholarship, with many maintaining 
the normative goals related to democracy and human dignity (as discussed in this Special Issue and revisited below) while most overlooking nuances of the rest.

One legacy of Lasswell has been the morphing of his decision functions into the policy cycle. ${ }^{1}$ As numerous textbooks testify, many of us are taught to conceptualize, organize, and communicate public policy through the policy cycle, and it has served as a way of describing the study of public policy. Yet, from gender policy studies to global policymaking, this Special Issue shows that the diversity of scholarship in the study of policy and politics transcends what the policy cycle conveys. We need broader and more inclusive descriptions of the course and cover of this field.

Confronting us all is the size and diversity of the field and how we conceive it. If we can imagine a map of this field, what would be its contours and reliefs, or its major nooks and crannies? This Special Issue and recent research in Policy \& Politics offer some suggestions of what constitutes this field. It involves mainstream or positive-oriented policy process theories (Heikkila and Jones, 2022), a world of research ranging from agenda-setting to diffusion (Hawkins and McCambridge 2020; Mallinson, 2021) and expertise to policy implementation (Christensen, 2021; Straßheim 2021; Moseley and Thomann 2021; Lee and Park 2021; Ball and Head 2021). It involves the study of meaning through the interpretation of language and discourse, as embedded, for example, in emotions (Durnová, 2022). It involves studies at different scales, from global policy studies and, of course, to local policy studies and their comparisons (Porto de Oliveira, 2022; McMullin et al., 2021; Dekker et al., 2021; Huang and Wiebrecht, 2021). Fundamentally, it must include studying different power relations in society, policies and politics, such as gender (Lombardo and Meier, 2022) or the intersection of various forms of oppression (Christoffersen, 2021). It must confront challenges in the relationship between the public and government (Moon and Cho, 2022; Dekker et al, 2021). Finally, as public policy is the fulcrum around which our politics of interest and ideas pivot, we must understand public policy design as a phenomenon in itself (Siddiki and Curley, 2022; Lewis et al., 2020; van Burren et al., 2020). And, unquestionably, it involves much more.

To the field, we ask the question: What then defines the study of policy and politics? One opening volley to prompt responses is to conceive this field simply through its words: the study of policy and politics is just that, the study of policy and politics, bottomless in depth and boundless in breadth. What defines its course and contours is not the phenomenon itself, as if it existed statically outside of our comprehension. Instead, as a community, we define what's in, what's out, and what's on the fuzzy borders. Of course, we expect our connotations of policy and politics to shift and change over time as we, as researchers, (re)conceive it over time. This definition, thus, hinges on the research foci, communication, and networks among committed scholars and a constant awareness of how we continuously dig deeper into its depths and usher its expansion in breadth through developing new ways of studying it. From the perspective of Policy \& Politics, we, as co-editors, encourage a broad definition - however it might materialize - that encompasses a diversity of approaches towards all things related to studying public policies and the surrounding politics. We are acutely aware that as editors of a top-quartile Public

\footnotetext{
${ }^{11}$ This might be one of the biggest misinterpretations in the study of public policy (see Dunn, 2019).
} 
Policy journal, we play a role as gatekeepers in the field. We make decisions every week of what falls inside and outside the journal's scope and, by extension, the study of policy and politics. And so, this is not an attempt to pretend that such gates do not exist. It is though an attempt to widen and heighten the gate through a continual redefinition of what the field is. We hope this Special Issue demonstrates such a conception.

\section{To what extent should our science be "normative" or "objective or "positive"?}

Many have interpreted Lasswell's message of conducting science for democracy and human dignity to mean that our research should somehow be normative in its orientation. From here, a two-sided debate ensued (see deLeon, 1998).

In one corner, we have arguments that, for example, policy change should include not just descriptions and explanations but assessments, including what is good or bad for democracy, who wins or loses from the decisions, or the impending effects on human dignity. This side also involves promoting critical theory towards uncovering power imbalances and situations of oppression and suppression and avoiding traditional theories that reinforce the status quo and the associated inequities by studying the status quo without judgment.

In the other corner, we have arguments of science for science's sake and its usual ally in conducting science based on objective or positive research. At times oblivious or indifferent to the external questions from critical theorists of harm from their science on the world, they defend the hill of reliability in generating knowledge and transparency in their methods (Yanow 2005).

Those in these corners have sparred for decades without resolution. However, the message from this Special Issue signifies that times are changing. Heikkila and Jones (2022) and Siddiki and Curley (2022), for example, incorporate questions of inequities into what has traditionally been positivist and objective orientations of research (see also arguments for incorporating emotions into policy theories by Pierce, 2021). Similarly, the inclusion of research on gender studies (Lombardo and Meier, 2022) (diverse in its approaches but too often disconnected from more objective research programs) and interpretive studies (Durnová, 2022) also prompts opportunities for constructive discussions and learning.

The growing recognition of normative scholarship in our disciplines has not taken place in a vacuum. The world of policy and politics that we explore has become increasingly polarized. What used to be seen as the neutral decision of doing science for science's sake is no longer neutral in a world where science and knowledge production is politicized (Christensen, 2021; Ylöstalo, 2020). It may then be that Foucault's knowledge-power nexus, always at the core of critical or interpretive policy studies, is making more sense to mainstream and positivist scholars. That is, there is a realization that even when we strive towards objectivity, our research can never be free from power relations. Researching the socio-political world must be methodologically rigorous and scientific, but the knowledge that we create can never be truly neutral. The choices we make in terms of what we study, how we study it and how we theorize, and conceptualize are often guided by scientific and other values. 
In this Special Issue, Heikkila and Jones (2022) address normativity head-on and discern implicitly normative stances in policy scholarship whilst calling for more contributions from explicitly normative perspectives. In such an effort, Durnová (2022) suggests increasing the use of ethnography and embracing normativity in research. Lombardo and Meier (2022) are equally explicit in their normative mission of producing scholarship that can contribute toward gender equality, with increasing emphasis on intersectional approaches. Moon and Cho (2022) are also quite open about public and communitarian citizenship being normatively desirable. Our other contributors' normative stances are perhaps more implicit. Nevertheless, the policy design scholarship that Siddiki and Curly (2022) engage with often has the same implicitly normative aim of increased efficiency that Heikkila and Jones (2022) identify in economics. Also implicitly normative is the cosmopolitan globalist ideal in Porto de Oliveira's (2022) piece about global public policy. If neo-populist far-right movements and nationalism are treated as threats to global public policy, then it follows that some cosmopolitan and internationalist values are normatively desirable.

Of course, not all research needs to be explicitly normatively oriented in assessing democracies and social and political inequities. Yet, the question for the field is how much of our individual and collective research should incorporate explicit normative ideas? And, if so, how should it be done? It also means we remove ourselves from our corners and engage in thoughtful discussions of whether and how this should be done.

\section{Who is our audience, and how do we engage them?}

As mentioned, Lasswell's charge could be simplified by the adage: knowledge to action. Yet, by focusing on whether and how to incorporate normative criteria into research based on Lasswell's policy sciences, we often overlook that the point of the policy sciences was just as much about normativity as it was about engagement. In other words, we often focus so much on incorporating normative criteria into our approaches that we forgot about the people who might be interested and affected by the research. Thus, what is missing in the field is discussions of how we conduct our research and how we reach our communities. We, thus, ask the question: Who are our audiences, and how do we engage them?

We suggest four ways to think about any response based on our intended audiences (see also deLeon and Weible, 2010). First, scholars shape other scholars' knowledge through publishing in academic journals. This is, of course, the bread and butter of scholars' work and impact, and should continue as such. Four decades ago, in his essays exploring the nature of the social sciences, Albert Hirschman (1981) noted that the common-sense understandings of social problems carried by us all makes it especially difficult for social scientific research to generate surprises. To do this we must take risks 'it must come up with something that has not been apparent or transparent before or, better still, with something that shows how badly commonsense understanding has led us astray' (1981: 298). We lay down the challenge to authors, and us as editors, to take more risks and challenge conventional wisdom more frequently.

Second, scholars' most crucial audience might be their students, reached through their teaching. Indeed, for many professors, their biggest impact on the world is probably their teaching, which 
sadly is often an area that receives less attention. It is also an audience that academic journals often ignore. For example, for journals, we might want to consider manuscripts that somehow relay knowledge about the field that might be common sense for established scholars but new and insightful for students. Where these students are practitioners (take, for example, those in the classic Masters in Public Administration programs), the power of policy studies is to provide a space for uncertainty, exploration, and co-production. These attributes are best facilitated by research that mirrors these aspirations - where binaries are challenged, and problems unpacked using robust but diverse methods (see Siddiki and Curley 2022 on policy design).

Third, and related more to Lasswell's vision, scholars' audience involves people outside of academia who are interested and affected by the research. Of course, Lasswell's vision owed much to John Dewey's pragmatism and the notion of knowledge as problem-solving (Dunn, 2019). Dewey's focus was on the life experiences of citizens where the central challenge of his age was to connect often distracted publics not interested in public policy problems with the essence of democracy - transforming the Great Society into the Great Community (Dewey, 1927). In this volume, Moon and Cho's (2022) analysis of citizenship, democracy, and COVID19 comes closest to aligning what works in policy research to an informed, engaged democratic public.

Narrowing the gap between academic research and the public - 'inquiry requires community' (Torgerson 1992: 231) - is no mean feat. We oversubscribe the strategy of reaching this audience through publishing in academic journals; too often, such research fails to reach them, is inaccessible, or is not timely. Instead, scholars could practice engaged scholarship and strive to conduct their research in conjunction with those interested and affected and share their research through non-academic outlets, from news media to trade magazines (Van de Ven, 2007).

Fourth, speaking of affected audiences, policy actors themselves are the subject of our work and the beneficiaries. A recent Policy \& Politics aimed to blaze a trail on this subject - challenging scholars to set their preferred theory of the policy process in dialogue with policy-makers (Weible and Cairney, 2018). We are also beginning to gather a clearer picture about the importance of academic research to a wide range of policy actors. The much-vaunted 'impact agenda' whereby the utility of our work for public life is periodically assessed is now institutionalized in government research audits in the UK, Australia, and Hong Kong. And in the last UK assessment, public policy research dominated, underpinning nearly a quarter of the case studies submitted by politics departments (Dunlop, 2018). High-quality research publications are an indispensable part of being able to 'speak truth to power' in this way (Wildavsky, 1979).

It is, however, important to note that the bulk of our impact concerns assessments of policy effectiveness, equality in public services and efficiency within individual policy sectors (Christoffersen 2021; Visintin et al., 2021; Ugyel and Daugbjerg, 2020; Dunlop, 2019). The big social challenges, or 'global megatrends' as Pollitt $(2016,2017)$ described them, like climate change, demography, fiscal contraction etc. were rarely addressed by policy research from political science. Moreover, despite long knowing that 'policies determine politics' (Lowi, 1972) big political science themes such as corruption and populism are too often left to political economists and electoral behaviour scholars. 
Possibly more important than these four simple strategies is the lack of sustained dialogue about our audiences and how we engage them.

\section{Whose knowledge matters, and how does it accumulate?}

As art is to aesthetics, science is to knowledge. For the sake of argument, let's define knowledge as our individual and collective understandings. Knowledge lies in our methods and methodologies, in the ontologies of our frameworks, theories, models, and other approaches, in our collective discourses. Each of the metacommunities comprising the study of policy and politics has a reservoir of knowledge that is ongoing in its evolution and taught and passed on among scholars and from instructors to students.

As different communities often operate from different ontological, epistemological, and methodological assumptions, their knowledge becomes inculcated through the various sources or signals of the world (broadly defined, including what some may consider data and others symbols) as reflected in their language, especially their ontologies. Knowledge then is not just a system of facts that can be communicated easily between communities. It involves, instead, words and concepts, each with meanings that require situational understandings to understand. Given our expectations drive our observations, much is lost in translation, misunderstood when communicating, or not translated at all. For example, the question coming to a common understanding is not as easy as agreeing that $1+1=2$ but whether we care to make such a calculation and the meaning of the number 1. And, thus, our metacommunities turn into a Tower of Babel: people with multiple languages cumbering their communication.

Different languages and communities might not be so much of a problem if they were somewhat equal in their footing, but with groups and categories comes hierarchies and privileges, that is, elevating some forms of knowledge over others. The question then becomes what is lost from such hierarchies and how to improve the situation. This is not the issue of sacrificing standards for the quality or integrity of research in the name of academic inclusion. It does, however, object to categorical exclusion irrespective of its quality.

In this Special Issue, several of our authors ask these foundational ontological, epistemological, and methodological questions. They do so in a way that promotes conversation between the metacommunities that we have brought together here. Heikkila and Jones (2022) historicize the discipline of public policy, from its scientific origins to now having two largely separate broad approaches to scholarship. What brings together the less scientific approaches, they say, is that they question one or more of causality, generalizability, and objectivity. It is fair to say that Heikkila and Jones are less optimistic than we are in terms of establishing fruitful collaboration and communication between different approaches. Nevertheless, the story told by Lombardo and Meier (2022) about scholarship on Gender and Policy Studies is one of bridging this divide. Gender itself is, of course, accepted as a social construct by all scholars in this metacommunity. It is therefore not surprising that social constructivist approaches and attempts to deconstruct gender and other power relations are common here. However, much of feminist policy scholarship is remarkably positivist and scientific in its approach. In seeking to bridge ontological, epistemological, and methodological divides, the rest of the field of policy and 
politics therefore have much to learn from how these divides have been bridged by gender and policy scholars.

Another way we can understand the divides between the scientific and less scientific can be learned from Robert Cox's differentiation between problem-solving and critical approaches to International Relations.

But whereas the problem-solving approach leads to further analytical subdivision and limitation of the issue to be dealt with, the critical approach leads toward the construction of a larger picture of the whole of which the initially contemplated part is just one component, and seeks to understand the processes of change in which both parts and whole are involved (Cox, 1981: 209).

For Cox, it was never a question of keeping the two approaches separate. Critical scholarship necessarily included problem-solving. Critical approaches have excelled in understanding power relations across race, gender, and class across the social sciences over the decades that have passed. When we look at mainstream or scientific scholarship in policy and politics today, there is no unwillingness to engage with these power relations. On the contrary, and no doubt as a result of increasing polarization around these questions in the world of policy and politics we study, we see a willingness to learn and incorporate key claims from critical scholarship into mainstream and more scientific analysis.

Thus, we ask the question: how can we develop the infrastructure in academia to bridge communities, develop shared languages, and build trust to enable critical and constructing questioning and collective learning across these divides?

\section{How should we advance the study of policy and politics?}

Readers should now surmise a general trend in how we, as editors of Policy \& Politics, conceive the strategies for responding to these questions in moving the field forward and upwards. First, we should embrace a comprehensive view of the field and dare to focus on the big challenges facing our world. Second, we should be inclusive in the different ways we conduct our science by embracing a pluralism in ontological, epistemological, and ontological orientations while avoiding categorical exclusions for reasons outside of quality. Third, we should welcome relevancy in our work, from bringing in normative criteria to conducting engaged scholarship. Of course, these three strategies are not mutually exclusive. They are fundamentally intertwined. Only by making our policy studies enterprise more ambitious and inclusive can we increase its analytical power and ultimately ensure its sustainability and continued relevance.

\section{Concluding remarks}

Like this Special Issue, Policy \& Politics will build on firm foundations (Marsh and Smith, 2022) to incite new research and excite new collaborations, and embolden scholars to use their 
metacommunities as the springboard to taking more risks. In addition, it seeks to support the integrity of the different research programs and metacommunities that populate the field of policy studies and create bridges between them. While breaking down the silos separating these communities remains unwise, building up knowledge from them offers both the means and ends for better ways of knowing and paths for growth.

For new and experienced scholars in policy and politics, the charge is not to compromise anyone's standards and approaches to science. Instead, the charge is to consider different ways of thinking about what we can discover and construct in the world, how we can conduct our science in doing so, and how our research contributes to understandings and knowledge within and beyond academia. Additionally, we can embrace the tensions and differences that lie at the crux of the cardinal challenges constituting the field, such as whether research should explicitly be normative and action-oriented or conducted for science-sake to contribute to the reservoirs of knowledge found among academic circles.

Let us agree that the world faces non-trivial challenges from the local to the global scales that, by necessity, require us to take an 'all hands on deck' mentality in growing our scholarly field and serving humanity. With its foci on global public policy studies, policy theories, policy design, gender studies, interpretive studies and emotions, and citizens, this Special Issue gives a glimpse at the potential learning and emergent questions and discussions from juxtaposing some - but not all - of the different traditions of scholars and scholarship.

As indicative of this Special Issue, Policy \& Politics, perforce, serves as the ecumenical journal to support and connect the different sects and strands in the studies of social policy, public policy, policy processes, and politics through a plurality of ontological, epistemological, and methodological orientations.

\section{References}

Ball, S., \& Head, B. W. (2021). 'Behavioural Insights Teams in Practice: Nudge Missions and Methods on Trial.' Policy \& Politics, 49(1):105-120.

Berglund, O. Dunlop C.A., \& Weible, C.M. (2021) 'Policy \& Politics: Serving and Enhancing our Metacommunities.” Policy \& Politics Journal Blog. 6 January 2021. [Accessed 22.10.21]

Christiansen, J. (2021) 'Expert knowledge and policymaking: a multi-disciplinary research agenda' Policy \& Politics 49 (3), 455-471

Christoffersen, A. (2021). The politics of intersectional practice: competing concepts of intersectionality. Policy \& Politics. Fast Track.

Cox, R. W. (1981) 'Social Forces, States and World Orders: Beyond International Relations Theory’ Millennium, 10(2):126-155.

Dekker, R., Oliver, C., \& Geuijen, K. (2021). 'Can Community Involvement Policies Mitigate NIMBYism and Local Opposition to Asylum Seeker Centres.’ Policy \& Politics. Fast Track. 
DeLeon, P. (1989). Advice and consent: The development of the policy sciences. Russell Sage Foundation.

DeLeon, P. (1998). 'Models of policy discourse: Insights versus prediction'. Policy Studies Journal, 26(1): 147-161.

Deleon, P., \& Weible, C. M. (2010). 'Policy Process Research for Democracy'. International Journal of Policy Studies, 1(2):23-34.

Dewey, J. (1927) The Public and its Problems New York, NY: Holt

Dunlop, C.A. (2018) 'The Political Economy of Politics and International Studies Impact: REF2014 Case Analysis', British Politics 13 (3): 270-294.

Dunlop, C.A. (2019) 'Bracing for Impact: Is Public Administration Ready to be Relevant?' in Massey, A. (ed) A Research Agenda for Public Administration Cheltenham: Edward Elgar, pp. 79-96.

Dunlop, C.A. and Radaelli, C.M. (2021) 'What is a Policy Scholar is For?' in Brik, A.B. and Pal, L.A. (eds) The Future of the Policy Sciences Cheltenham: Edward Elgar.

Dunn, W. N. (2019). Pragmatism and the Origins of the Policy Sciences: Rediscovering Lasswell and the Chicago School. Cambridge University Press.

Hawkins, B., \& McCambridge, J. (2020). 'Policy Windows and Multiple Streams: An Analysis of Alcohol Pricing Policy in England.' Policy and Politics, 48(2): 315-333.

Hirschman, A.O. (1981) Essays in Trespassing: Economics to Politics and Beyond, Cambridge, MA: Cambridge University Press.

Huang, B., \& Wiebrecht, F. (2021). 'The Dynamic Role of Governments in Adopting Policy Innovations in China.' Policy \& Politics. Fast Track

Lasswell, H. D. (1948). Power and personality. New Brunswick.

Lasswell, H.D. (1951). 'The Policy Orientation', In D. Lerner and H.D. Lasswell, eds., The Policy Sciences: Recent Developments in Scope and Method. Stanford: Stanford University Press, pp. 3-15.

Lee, D. S., \& Park, S. (2021). 'What Motivates Street-Level Bureaucrats to Implement the Reforms of Elected Politicians?' Policy \& Politics, 49(1): 141-160.

Lewis, J. M., McGann, M., \& Blomkamp, E. (2020). 'When Design Meets Power: Design Thinking, Public Sector Innovation and the Politics of Policymaking.' Policy \& Politics, 48(1): 111-130.

Lowi, T. (1972) 'Four Systems of Policy, Politics and Choice' Public Administration Review 32 (4): 298-310.

Mallinson, D. J. (2021). 'Growth and Gaps: A Meta-Review of Policy Diffusion Studies in the American States.' Policy \& Politics. 49(3): 369-389. 
Marsh, A. and Smith, R. (2022) 'Policy and Politics: A perspective on the first half century' Policy \& Politics XXXX

McMullin, C., Roy, M. J., \& Curtin, M. (2021). 'Institutional Logics as a Framework for Understanding Third Sector Development: An Analysis of Quebec and Scotland.' Policy \& Politics. Fast Track.

Moseley, A., \& Thomann, E. (2021). 'A Behavioural Model of Heuristics and Biases in Frontline Policy Implementation.’ Policy \& Politics, 49(1): 49-67.

Pierce, J.J. (2021). "Emotions and the Policy Process: Enthusiasm, Anger, and Fear." Policy \& Politics Fast track.

Pollitt, C. (2016) 'Be Prepared? An Outside-In Perspective on the Future Public Sector in Europe' Public Policy and Administration 31 (1): 3-28.

Pollitt, C. (2017) 'Public Administration Research since 1980: Slipping Away from the Real World? International Journal of Public Sector Management, 30 (6-7): 555-565.

Straßheim, H. (2021). 'Who are Behavioural Public Policy Experts and How are They Organised Globally?' Policy \& Politics, 49(1): 69-86.

Torgerson, D, 1992, Priest and jester in the policy sciences: Developing the focus of inquiry, Policy Sciences, 25, 3, 225-235

Ugyel, L., \& Daugbjerg, C. (2020). 'Successful Policy Transfer and Public Sector Reform in Developing Countries.' Policy \& Politics, 48(4): 603-618.

van Buuren, A., Lewis, J.M., Peters, B.G. and Voorberg, W. (2020) 'Improving Public Policy and Administration: Exploring the Potential of Design' Policy \& Politics 48 (1): 3-19.

Van de Ven, A. H. (2007). Engaged scholarship: A guide for organizational and social research. Oxford University Press on Demand.

Visintin, E. P., Bonvin, J. M., Varone, F., Butera, F., Lovey, M., \& Rosenstein, E. (2021). 'Can Street-Level Bureaucrats be Nudged to Increase Effectiveness in Welfare Policy?' Policy \& Politics, 49(1):121-139.

Weible, C. M., \& Cairney, P.A. (2018). 'Practical lessons from policy theories. Policy \& Politics' 46(2): 183-197.

Wildavsky, A. (1979) Speaking Truth to Power: The Art and Craft of Policy Analysis Boston, MA: Little, Brown and Company.

Yanow, D. (2005) 'In the house of "science," there are many rooms: Perestroika and the "science studies" turn' In K. R. Monroe (Ed.), Perestroika! The raucous rebellion in political science (pp. 200-217) New Haven, CT: Yale University Press

Ylöstalo, H. (2020). 'The Role of Scientific Knowledge in Dealing with Complex Policy Problems under Conditions of Uncertainty’. Policy \& Politics, 48(2): 259-276. 